\title{
An electrochemical DNA sensor without electrode pre-modification
}

\author{
Nian Hong ${ }^{1}$, Lin Cheng ${ }^{1}$, BingGuo Wei ${ }^{1}$,ChaDan Chen ${ }^{1}$, Ling Ling $\mathrm{He}^{1}$, DeRong \\ kong $^{1}$, JinXiang Ceng ${ }^{2}$, Han-Feng Cui ${ }^{1} *$, Hao Fan $^{1} *$ \\ ${ }^{1}$ Department of Pharmacy, JiangXi University of Traditional Chinese Medicine, \\ JiangXi 330004 (China). \\ ${ }^{2}$ The Research Center of Chinese Medicine Resource and National Medicine of Jiang \\ Xi University of Traditional Chinese Medicine, JiangXi 330004 (China).
}

\section{Corresponding Author}

Phone: (+86) 791-7118918 Fax: (+86) 791-7118919

E-mail addresses: fanhao11@aliyun.com (H. Fan), cuihanfeng@126.com(H.F.Cui) 


\section{ABSTRACT}

We present a non-modification electrochemical DNA sensing strategy, which used Potential-Assisted Au-S Deposition and a clamp-like DNA probe. The dual-hairpin probe DNA was tagged with a methylene blue (MB) at the 3' terminal and a thiol at the 5' terminal., Without being hybridized with target DNA, the loop of probe prevented the thiol from reaching the bare gold electrode surface with an applied potential., After hybridization with the target DNA, the probe' s loop-stem structure opened through two distinct and sequential events, which led to the formation of a triplex DNA structure. Then the thiol easily contacted with electrode and resulted in potential-assisted Au-S self-assembly. Electrochemical signals of MB were measured by differential pulse voltammetry (DPV) and used for target quantitative detection. This strategy offered a detection limit down to $2.3 \mathrm{pM}$ and an inherently high specificity for detecting even single mismatch.

KEYWORDS: non-modification, electrochemical DNA sensor, homogenous sensing, Potential-Assisted, Clamp-like DNA probe

\section{Introduction}

Nucleic acids are one of the most fundamental molecules for all life forms, and as a result the specific nucleic acid sequence quantification is essential in biological and biomedical studies, such as medical diagnostics, gene expression analysis, and the 
detection of infectious diseases. Until now, many approaches have been successfully developed for the sequence-selective DNA hybridization examination, including optical (Ma et al.,, 2013 ; Garcíamartinez et al.,, 2011), mass-sensitive ( Zhao et al.,,, 2014), fluorescent (Zhao et al., 2012), chemiluminescent (Liu et al., 2013) and electrochemical methods (Lazerges and Bedioui 2013; Hu et al., 2012; Tang et al., 2013).

The electrochemical DNA sensing technology has received particular attention mostly due to its high sensitivity, selectivity and easy operation with simple instrumentations(Nakayama et al., 2002; Patolsky et al., 2001; Ting et al., 2009; Cho et al., 2006).

Generally, the electrochemical DNA sensors are based on DNA hybridization. The electrochemical signal that produced by probe hybridized with target DNA is used for qualitative and quantitative detection. Based on hybridization type, the electrochemical sensors were divided into two categories: heterogeneous hybridization(Cai et al., 2002 ; Wang 2006 ; Li et al., 2014 ; Song and Jin 2015 ; Ionescu et al., 2006) and homogeneous hybridization(Cui et al., 2014 ; Fan et al., 2011a ; Fan et al., 2011b ; Fan et al., 2010).

Among heterogeneous hybridization types, the electrochemical DNA (E-DNA) sensor have attracted much attention(Immoos et al., 2004 ; Xiao et al., 2007 ; March et al., 2008) due to its reagentless, simple operation and regeneration. Broadly, the reagentless, single-step E-DNA sensors could be classified into "signal-on" and "signal-off” two types. In a "signal-off" sensor, the mechanism is the alternation of 
distance of the labeled redox tags from the electrode by target DNA-induced conformational change of probe. "Signal-off” sensors are more susceptible to "false positive" results; the reduction in signal could be due to events other than target binding. Researchers have shifted their focus to the development of "signal-on" E-DNA sensors (Rowe et al., 2011; Guo 2002 ; Farjami et al., 2011).

“Signal-on” sensors can achieve much improved signaling, and the background current observed in the absence of target is reduced, the gain of such a sensor, at least in theory, increases without limit. In the signal-on sensors, target hybridization enhances the rate which the redox moiety approaches the electrode, avoids false positives and leads to a current increase. However, hybridization signal increase is limited to the length of the probe, signal-on E-DNA sensor usually bears low sensitivity. The signal-on E-DNA sensors need probe DNA pre-immobilization on the electrode surface, which causes lower available hybridization efficiency when compared with the sensors with hybridization happens in homogeneous solution, thus facing the difficulty for real-time electrochemical monitoring PCR and recognizing specific sequence DNA in living cells.

As a result, we had developed the non-immobilizing electrochemical DNA sensing strategy to overcome some shortcomings. This type of sensor avoided immobilizing probe DNA on electrode surface and hybridization event occurred in a homogeneous solution which made it have the high sensitivity(Cui et al., 2014 ; Fan et al., 2011b; Fan et al., 2011a ; Fan et al., 2010). However, the necessary modifications on probe DNA and electrode surface made the non-immobilizing electrochemical DNA 
sensors more complex than E-DNA sensor. How to obtain a simple and efficient DNA sensor becomes the goal of researchers to pursue.

In the present study, we developed a non-modification electrochemical DNA homogenous sensing strategy based on Potential-Assisted Au-S Deposition.

The scientists have found that the chemisorption of the alkanethiol can be controlled electrochemically(Weisshaar et al., 1992; And and Rubinstein 1998). A modest anodic potential was applied to the gold electrode during RSH adsorption very quickly, and high-quality Self-Assembled Monolayers(SAMs) with excellent performance characteristics was formed. This potential deposition process also allowed precisely controlling the ratio of components in a model binary SAM made up of $\mathrm{C}_{16} \mathrm{SH}$ and $\mathrm{HSC}_{15} \mathrm{CO}_{2} \mathrm{H}$. The DNA self-assembly process was performed under potential control because it was shown that the application of low positive potentials to the gold surface accelerates the chemisorption process and may assist in organizing the monolayer(And and Lennox 2000).

Using potential-assisted Au-S chemisorption and clamp-like mechanism (Idili et al., 2014), we constructed a very simple electrochemical sensor for DNA homogenous detection. Based on the clamp-like mechanism, we have developed a clamp-like DNA probe that recognizes a specific complementary oligonucleotide target through both Watson-Crick and triplex-forming Hoogsteen interactions can improve both the affinity and specificity of recognition(Idili et al., 2013). As figure 1 showed, before the hybridization, the probe DNA in which 3' terminal was modified methylene blue (MB) and 5' with thiol(HS) adopted stem-loop structure and thus the HS was forced 
to be locked in the stem-loop. Due to the steric effect of the stem-loop structure of probe DNA, the HS was prevented from reaching the gold electrode surface with an applied potential., After being hybridized with the target DNA, the probe's loop-stem structure opened and then HS could easily contact with electrode and resulted in potential-assisted Au-S self-assembly. Therefore, the target hybridization event can be sensitively transduced via detecting the electrochemical signal of the MB-labeled probe.

Figure 1

\section{Experimental section}

\subsection{Materials}

The oligonucleotide sequences used in this work were purchased from the Takara Biotechnology Company (DaLian, China) as desalted products, and their sequences are listed below. The oligonucleotides were purified via the C18 reversed-phase HPLC and polyacrylamide gel electrophoresis (PAGE).

The non-clamp-switch probe (P1) sequence is as follows: 5'-HS-( $\left.\mathrm{CH}_{2}\right)_{6}$-GGAATTTATTCC GGTTATCTCTATAATACTAACC-MB-3'. The probe is modified at the 5 '-end with a thiol and at the $3^{\prime}$-end with a MB redox label, which will form the stem. The clamp-switch probe(P2) sequence is as follows: 5'-HS-( $\left.\mathrm{CH}_{2}\right)_{6}$-GGAATTTATTCCGGTTATCTCTCCTTATTTAACC-MB-3'. The probe is modified at the 5 '-end with a thiol and at the $3^{\prime}$-end with a methylene blue (MB) redox label, which will form the stem at appropriate ionic strength.

The sequence of the target (oligo 3:) is perfectly matched to the partial sequence of 
the probe; oligo 4 contains a one-base mismatch, while oligo 5 has three-base mismatches. Oligo 6 is a random sequence unrelated to the probe sequence.

\author{
oligo 3: 5'- CCGGAATAAATTCC-3' \\ oligo 4: 5'- CCGGTATAAATTCC-3' \\ oligo 5: 5'- CCGGTTAAAATTCC-3' \\ oligo 6: 5'- GGCCTTATTTAAGG-3'
}

Unless otherwise noted, all chemicals were purchased from Dingguo Biotechnology Inc. (Shanghai, China) and were of analytical reagent grade. All of the solutions were prepared with ultrapure water from a Millipore Milli-Q system.

To reduce the S-S bonds and obtain the SH terminal groups, these products were treated with $10 \mathrm{mM}$ Tris(2-Carboxyethyl)Phosphine Hydrochloride(TCEP, Sigma, Spain) for $1 \mathrm{~h}$ at room temperature. The DNA-SH obtained was purified by passing through a Sephadex G25 column (NAP-10, Pharmacia Biotech). After elution with Milli-Q water, the concentration of the thiolated oligonucleotide was measured spectrophotometrically at $260 \mathrm{~nm}$ and subsequently stored at $-20^{\circ} \mathrm{C}$. Stock solutions of $5.5 \mu \mathrm{M}$ oligonucleotide were stored at $4{ }^{\circ} \mathrm{C}$ and diluted with $10 \mathrm{mM}$ PBS buffer ( $\mathrm{pH}$ 8.0) buffer solution prior to use as needed for each specific experiment.

\title{
2.2 Apparatus
}

Voltammetric and chronocoulometric experiments were performed using an autolab electrochemical workstation (Metrohm Instruments Co., Swiss). The conventional three-electrode system was employed for all the measurements. A platinum wire served as counter electrode and a $\mathrm{Ag} / \mathrm{AgCl} / \mathrm{KCl}($ sat.) electrode as reference. The 
working electrode was a $1.0 \mathrm{~mm}$ diameter polycrystalline gold electrode. Elimination of organic matter from the gold surface was achieved by cleaning it in piranha solution $\left(30 \% \mathrm{H}_{2} \mathrm{O}_{2}\right.$ and $70 \%$ concentrated $\mathrm{H}_{2} \mathrm{SO}_{4}$; Caution: piranha solution is strongly oxidizing and should be handled with care!) for 10 min. Then the electrode was rinsed with Milli-Q water, and the surface was mechanically polished using slurries of alumina (1, 0.3, and $0.05 \mu$ m diameter successively, Buehler, Germany) on a polishing pad and ultrasonicated with Milli-Q water. To obtain reproducible surface conditions(Campuzano et al., 2002), the electrode was subsequently immersed for $1 \mathrm{~h}$ in a hot $2 \mathrm{M} \mathrm{KOH}$ solution, rinsed with water, immersed in concentrated $\mathrm{H}_{2} \mathrm{SO}_{4}$ for 10 min, rinsed with water, immersed in concentrated $\mathrm{HNO}_{3}$ for $10 \mathrm{~min}$, and thoroughly washed with Milli-Q water. The cleaned gold surface was checked by cyclic voltammetry in an oxygen-free $0.1 \mathrm{M} \mathrm{H}_{2} \mathrm{SO}_{4}$ solution, between 0 and $1.6 \mathrm{~V}$, until an ideal redox wave of polycrystalline gold was obtained. The electrochemical surface area was calculated from the charge corresponding to the reduction of gold oxides(Tremiliosifilho et al., 1997).

The fluorescence spectra were recorded at room temperature in a quartz cuvette on an F-4500 spectrophotometer (Hitachi, Japan).The excitation wavelength was $480 \mathrm{~nm}$, and the emission wavelengths were in the range 510-600 nm with both excitation and emission slits of $5 \mathrm{~nm}$.

\subsection{Potential-Assisted Au-S Deposition on electrode}

The DNA self-assembly process was performed under potential control because it 
was shown that the application of low positive potentials to the gold surface accelerates the chemisorption process and may assist in organizing the monolayer. The clean gold electrode was initially subjected to $0.3 \mathrm{~V}$ for $5 \mathrm{~min}$ in order to ensure a reduced gold surface. Subsequently the electrode was immersed in $400 \mu \mathrm{L}$ of $0.2 \mu \mathrm{M}$ capture probe and incubated for 5 min under an applied potential of $0.4 \mathrm{~V}$. The electrode was then thoroughly rinsed with water to remove the weakly adsorbed DNA.

\subsection{DNA sequence sensing performance}

The DNA assay procedure was initiated in $10 \mathrm{mM}$ phosphate buffer (PBS) containing $3.0 \mathrm{mM} \mathrm{Mg}^{2+}$ by adding $10 \mu \mathrm{L}$ of $0.4 \mu \mathrm{M}$ probe to target DNA and stirring the mixture for $40 \mathrm{~min}$ at $45{ }^{\circ} \mathrm{C}$. During the process, the target DNA hybridized with probe DNA, and then the cleaned gold electrode was immersed in the solution for probe-target DNA hybridization. After 5 minutes potential-Assisted Au-S Deposition Procedure, the electrode was washed with a $0.1 \%$ sodium dodecyl sulfate (SDS) phosphate buffer ( $\mathrm{pH}$ 7.3) to remove the non-specific adsorption.

The electrochemical investigation was carried out in a $3 \mathrm{ml}$ electrochemical cell with the resulted gold working electrode, an $\mathrm{Ag} / \mathrm{AgCl}$ reference electrode and the platinum wire counter electrode by DPV. The electrochemical signal of the MB was obtained in the $10 \mathrm{mM}$ PBS buffer (pH 7.3) at about $-0.20 \mathrm{~V}$ (versus $\mathrm{Ag} / \mathrm{AgCl}$ ).

\section{Results and Discussion}

\subsection{Sensor Design.}


In this sensor, the probe was the only necessary component to be designed. The configuration change of probe would determine the sensor performance reacting to target hybridization. For this reason, the probe with the dual-stem-loop structure was designed. Mfold Web Server [32] and fluorescence experiments were used to predict the solution-phase conformation of this sequence(see supporting information). And it was predicted that in the hybridization conditions adopted by the analysis, only one secondary structure (the dual-stem-loop structure) is thermodynamically stable, which confirmed the suitability of the chosen sequence.

Two different probes with complementary sequence in same location were tested (Figure 2). Mfold Web Server was used to predict the solution-phase conformation of probes after being hybridized with target. When using P1, it was possible to distinguish between sample and background and a linear rigid duplex was formed on the electrode surface. And using P2, it obtained the higher target/background signals which formed an appropriate clamp-conformation. Our clamp-switch probe is composed of two recognition elements. The first recognition element, a 14-bases complementary sequence (gray portion), binds the target via Watson-Crick base pairing. The second recognition element, a 10-bases sequence (red portion), then binds the so-formed duplex via sequence-specific Hoogsteen base pairing[28]. The formation of this triplex structure occurs through a conformational switch that leads to its closure.

\section{Figure 2}

The fluorescence experiments were performed to serve as a proof of the 
clamp-conformation of the electrochemical probe DNA(Figure 3).

The Fluorescence probe was synthesized with the same sequence as P2 (5’FAM-(CH2)6-GGAATTTATTCCGGTTATCTCTCCTTATTTAACC-3’).

fluorophore 6-FAM was attached to $5^{\prime}$ end of the sequence. And target DNA( $5^{\prime}$ DABCYL-CCGGAATAAATTCC-3' ) with a quencher DABCYL was attached to the $5^{\prime}$ end. In absence of target DNA, the emission spectrum for fluorescence probe is presented in Figure $3 \mathrm{~B}$ as the red curve. After being hybridized with target DNA, the fluorescence was quenched approximately $65 \%$ in relation to a pure $50 \mathrm{nM}$ fluorescence probe solution, from I1 605 to I2 210. It indicates that a appropriate clamp-conformation brings the quencher and fluorophore close together that turns the probe to the "OFF" state.

\section{Figure 3}

\subsection{Comparison experiment of potential-Assisted Au-S Deposition}

The experiment was performed to compare the efficiency of Au-S deposition. First, a $3.2 \times 10^{-10} \mathrm{M}$ complementary DNA target was incubated with clam probe to obtain triplex DNA structure. These hybridizers were incubated with Au electrode in different assisted conditions for 5 minutes. As figure 4 shown, a negative current was obtained without potential-Assisted Au-S Deposition, which indicated almost no hybridizer was immobilized on electrode. This result consistent with previous reported that Au-S deposition consume an enormous amount of time without potential-assisted (Rowe et al., 2011; Guo 2002 ; Farjami et al., 2011). However, with potential-Assisted Au-S Deposition, the numerous hybridizers were immobilized on 
electrode result in a obvious current increase.

\section{Figure 4}

\subsection{Optimization of detection condition}

A series of experimental was performed to establish optimal DNA detection conditions, including hybridization temperature, hybridization time, $\mathrm{Mg}^{2+}$ ion concentration, hydrogen ion concentration $(\mathrm{pH})$, Potential-Assisted Au-S Deposition time. (see supporting information)

The increased current intensity ( $\Delta \mathrm{I}=\mathrm{Is}-\mathrm{I}_{0}$ ) was used for evaluated optimization experimental, where $\mathrm{I}_{0}$ and $\mathrm{I}_{\mathrm{S}}$ were the current intensity of the DNA biosensor before and after incubation with target, respectively.

In this study, a $3.2 \times 10^{-10} \mathrm{M}$ complementary DNA target was incubated with clam probe at a series of temperatures ranging from 30 to $50{ }^{\circ} \mathrm{C}$. As shown in Supporting Information Figure S3, the highest signal is obtained at $45{ }^{\circ} \mathrm{C}$. Therefore, a hybridization temperature of $45{ }^{\circ} \mathrm{C}$ was selected in the following experiments. The effect of the hybridization time has also been investigated. The target DNA was incubated with target DNA at $45{ }^{\circ} \mathrm{C}$ for different times from 20 to $50 \mathrm{~min}$. The signal responses of the assay to the different hybridization times are shown in Supporting Information Figure S4. It can be seen from this figure that the signal increases rapidly when the hybridization time increases from 20 to $40 \mathrm{~min}$ and then increases slightly from 40 to $50 \mathrm{~min}$, indicating that the hybridization reaches equilibrium at $40 \mathrm{~min}$. As a result, a reaction time of 40 min was selected for the DNA hybridization. 
The cation $\mathrm{Mg}^{2+}$ plays an important role in DNA hybridization. For a dual-hairpin DNA probe-based DNA assay, there is hybridization competition between intramolecular stem part hybridization and intermolecular target DNA-probe hybridization. Therefore, $\mathrm{Mg}^{2+}$ concentration in the hybridization buffer should be balanced. Although a high concentration of $\mathrm{Mg}^{2+}$ can enhance target DNA hybridized to the loop of the structure, it may also strengthen the binding of the stem part of the probe, which may adversely affect the performance of the assay. Supporting Information Figure S5 shows the effect of $\mathrm{Mg}^{2+}$ concentration in the hybridization buffer on the response signal of the assay. As shown in this figure, the assay produces the highest signal when the $\mathrm{Mg}^{2+}$ concentration is $3 \mathrm{mM}$. Accordingly, a $3 \mathrm{mM} \mathrm{Mg}^{2+}$ concentration was used throughout the experiments to obtain the highest signal.,

As a result, a series of optimized parameters were obtained and used for DNA detection as section 2.4.

\subsection{Detection performance of target DNA}

Figure 4A shows representative DPV signals of different sensors hybridized under optimal experimental conditions with increasing concentrations of target DNA. The response signal increases with the increase of target concentration in the range $3.2 \times$ $10^{-12} \mathrm{M}$ to $3.2 \times 10^{-7} \mathrm{M}$. The calibration curve is shown in Figure $5 \mathrm{~A}$. The equation for the resulting calibration plot was calculated as $y=0.2435 \log x+3.01459$ ( $x$ is the concentration of target DNA divided by pM, y is the DPV peak current value) with correlation coefficient of 0.9969 and detection limit of $2.3 \times 10^{-12} \mathrm{M}(>3 \mathrm{SD})$. This 
sensitivity reflected the high signal amplification of this method and the improved signal gain as a signal-on sensor used MB as indicators.

In order to confirm the binding specificity of the clamp-switch probe to the target DNA, control experiments were performed by using different DNA sequences to hybridize with $0.4 \mu \mathrm{M}$ clamp-switch probe, including complementary DNA, one base-mismatched DNA, three base-mismatched DNA and non-complementary DNA. As shown in Figure 5B the non-complementary DNA produced a neglectable DPV signal (signal (b)), which was similar to that of the background signal (signal (a)), and when compared to the complementary sequence (signal (e)), the three base-mismatched DNA produced a very low insignificant DPV signal (signal (c)), and the one base-mismatched DNA generated a one fourth signal (signal (d)). We propose that this sequence specificity of the clamp-switch probe is mainly due to the intrinsic recognition ability of DNA bases, and also related to that even if the probe is hybridized with mismatched target, the probe DNA's hairpin structure is partially opened, an obvious steric effect still exists for such "hybridizer" to contact the electrode.

\section{Figure 5}

\section{Conclusion}

In summary, we completed a non-modification electrochemical DNA homogeneous sensing strategy based on the use of the Potential-Assisted Au-S Deposition and a clamp-like DNA-based probe. Without being hybridized with target DNA, the loop of 
probe prevented the thiol from reaching the bare gold electrode surface with an applied potential., After hybridization with the target DNA, the probe' s loop-stem structure opened through two distinct and sequential events, which led to the formation of a triplex DNA structure. Then the thiol easily contacted with electrode and resulted in potential-assisted Au-S self-assembly. Electrochemical signals of MB were measured by differential pulse voltammetry (DPV).This assay protocol is simple, convenient and cost-effective. As a result, we could conveniently detect as few as $2.3 \times 10^{-12} \mathrm{M}$ target DNA.

Up to data, almost all of the E-DNA sensor need to fix the probe on the surface of gold electrode. It will lead to two disadvantages. One is the Au-S deposition consume an enormous amount of time without potential-assisted, and the other is redox-label of the probe gets close to the surface of gold electrode, $\mathrm{w}$ hich causes big background current and this limits the detection sensitive. However our sensor successfully overcome these shortcomings. We propose that it might be a promising approach to perform DNA-based diagnostics where resources are limited, such as small clinics in developing countries or field detection.

\section{ACKNOWLEDGMENT}

We gratefully acknowledge the financial support from the NSF of China (Grant No. 21265007,81560625) and JiangXi Science and Technology Committee Foundation(Grant No. 20151512040663 ), JiangXi Education Science Foundation (No. GJJ14610, GJJ14620). 


\section{References}

Cai, H., Wang, Y., He, P., Fang, Y., 2002. Anal. Chim. Acta. 469, 165-172.

Campuzano, S., Gálvez, R.o., Pedrero, M.a., de Villena, F.J.M., Pingarrón, J.M., 2002. J. Electroanal. Chem. 526, 92-100.

Cho, M., Lee, S., Han, S.Y., Park, J.Y., Rahman, M.A., Shim, Y.B., Ban, C., 2006. Nucleic. Acids. Res. 34, : e75.

Cui, H.-F., Cheng, L., Zhang, J., Liu, R., Zhang, C., Fan, H., 2014. Biosensors and Bioelectronics, 56, 124-128.

Fan, H., Xing, R., Xu, Y., Wang, Q., He, P., Fang, Y., 2010. Electrochem. Commun. 12, 501-504.

Fan, H., Xu, Y., Chang, Z., Xing, R., Wang, Q., He, P., Fang, Y., 2011a. Biosensors and Bioelectronics, 26, 2655-2659.

Fan, H., Zhao, K., Lin, Y., Wang, X., Wu, B., Li, Q., Cheng, L., 2011b. Anal. Biochem. 419, 168-172.

Farjami, E., Clima, L., Gothelf, K., Ferapontova, E.E., 2011. Anal. Chem. 83, 1594-1602.

Garcia-Martinez, G., Bustabad, E.A., Perrot, H., Gabrielli, C., Bucur, B., Lazerges, M., Rose, D., Rodriguez-Pardo, L., Farina, J., Compere, C., Vives, A.A., 2011. Sensors (Basel). 11, 7656-7664.

Guo, Y.-G., Wan, L.-J., Gong, J.-R., Bai, C.-L., 2002. Phys. Chem. Chem. Phys. 4, 3422-3424.

Hu, Y., Li, F., Han, D., Wu, T., Zhang, Q., Niu, L., Bao, Y., 2012. Anal. Chim. Acta. 753, 82-89.

Idili, A., Amodio, A., Vidonis, M., Feinberg-Somerson, J., Castronovo, M., Ricci, F., 2014. Anal. Chem. 86, 9013-9019.

Idili, A., Plaxco, K.W., Vallée-Bélisle, A., Ricci, F., 2013. ACS Nano. 7, 10863-10869.

Immoos, C.E., Lee, S.J., Grinstaff, M.W., 2004. J. Am. Chem. Soc. 126, 10814-10815.

Ionescu, R.E., Herrmann, S., Cosnier, S., Marks, R.S., 2006. Electrochem. Commun. 8, 1741-1748.

Lazerges, M., Bedioui, F., 2013. Analytical and Bioanalytical Chemistry, 405, 3705-3714.

Liu, M., Li, B., Cui, X., 2013. Biosensors and Bioelectronics. 47, 26-31.

Ma, F., Lennox, R.B., 2000. Langmuir. 16, 6188-6190.

Ma, W., Kuang, H., Xu, L., Ding, L., Xu, C., Wang, L., Kotov, N.A., 2013. Nat Commun. 4, 2689.

March, G., Noël, V., Piro, B., Reisberg, S., Pham, M.-C., 2008. J. Am. Chem. Soc. 130, 15752-15753.

Nakayama, M., Ihara, T., Nakano, K., Maeda, M., 2002. Talanta. 56, 857-866.

Patolsky, F., Lichtenstein, A., Willner, I., 2001. Nat Biotech. 19, 253-257.

Ron, H., Rubinstein, I., 1998. J. Am. Chem. Soc. 120, 13444-13452.

Rowe, A.A., Chuh, K.N., Lubin, A.A., Miller, E.A., Cook, B., Hollis, D., Plaxco, K.W., 2011. Anal. Chem. 83, 9462-9466.

Song, M.-J., Jin, J.-H., 2015. Anal. Sci. 31, 159-163.

Tang, J., Zhou, J., Li, Q., Tang, D., Chen, G., Yang, H., 2013. Chem. Commun. 49, 1530-1532.

Ting, B.P., Zhang, J., Gao, Z., Ying, J.Y., 2009. Biosensors and Bioelectronics, 25, 282-287.

Tremiliosifilho, G., Dallantonia, L.H., Jerkiewicz, G., 1997. J. Electroanal. Chem. 422, 149-159.

Wang, J., 2006. Biosensors and Bioelectronics. 21, 1887-1892.

Wang, L., Hua, E., Liang, M., Ma, C., Liu, Z., Sheng, S., Liu, M., Xie, G., Feng, W., 2014. Biosensors and Bioelectronics, 51, 201-207.

Weisshaar, D.E., Lamp, B.D., Porter, M.D., 1992. J. Am. Chem. Soc. 114, 5860-5862.

Xiao, Y., Qu, X., Plaxco, K.W., Heeger, A.J., 2007. J. Am. Chem. Soc. 129, 11896-11897.

Zhao, X.-H., Ma, Q.-J., Wu, X.-X., Zhu, X., 2012. Anal. Chim. Acta. 727, 67-70. 
Zhao, Y., Xu, L., Ma, W., Liu, L., Wang, L., Kuang, H., Xu, C., 2014. Small, 10, 4770-4777. 
Figure 1. Scheme for the non-modification electrochemical DNA sensor.

Figure 2, Scheme for the different Probes used in target detection.

Figure 3, (A) Scheme for Fluorescence clamp-conformation behavior of the fluorescence probe. (B) Fluorescence emission spectra of a $50 \mathrm{nM}$ fluorescence probe (red curve). after hybridized with target DNA (blue curve). buffer $10 \mathrm{mM}$ MOPS containing $50 \mathrm{mM} \mathrm{NaNO} 3$;

Figure 4, DPV response of the hybridizer self-assembled on $\mathrm{Au}$ electrode without potential-assisted deposition (a), with potential-assisted deposition (b).

Figure 5, (A) DPV response of clamp-probe in the solution containing $0 \mathrm{M}$ (a), $3.2 \times 10^{-12} \mathrm{M}(\mathrm{b}), 3.2 \times 10^{-11} \mathrm{M}(\mathrm{c}), 3.2 \times 10^{-10} \mathrm{M}(\mathrm{d}), 3.2 \times 10^{-9} \mathrm{M}(\mathrm{e}), 3.2 \times 10^{-8} \mathrm{M}(\mathrm{f})$ target DNA. (Insert) The calibration plots of target DNA $\left(3.2 \times 10^{-12}\right.$ to $\left.3.2 \times 10^{-8} \mathrm{M}\right)$.(B) The comparison of the DPV signal of MB when the clamp-probe hybridized with only the hybridization buffer containing no DNA sequences (a), $3.2 \times 10^{-8} \mathrm{M}$ non-complementary DNA (b) $3.2 \times 10^{-8} \mathrm{M}$ three base-mismatched DNA (c), $3.2 \times 10^{-8} \mathrm{M}$ one base-mismatched DNA (d), $3.2 \times 10^{-10} \mathrm{M}$ target DNA(e). 
Figure 1

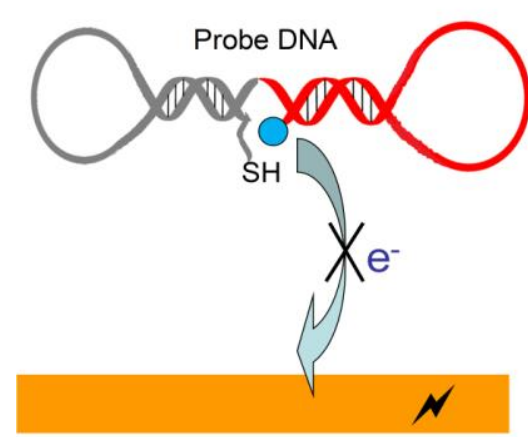

Bare $\mathrm{Au}$ electrode

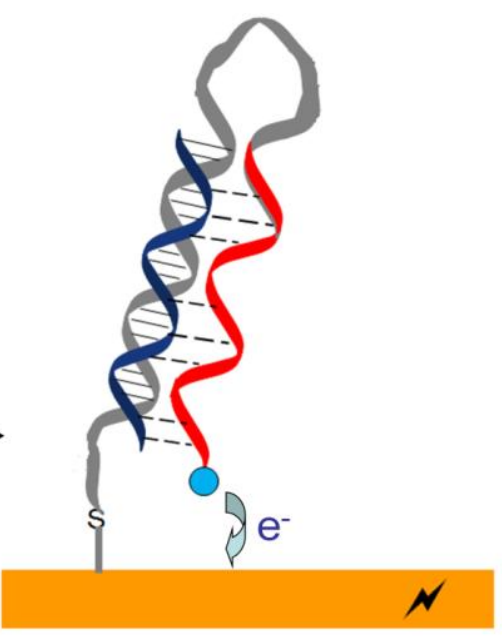

Bare $\mathrm{Au}$ electrode

Figure 2

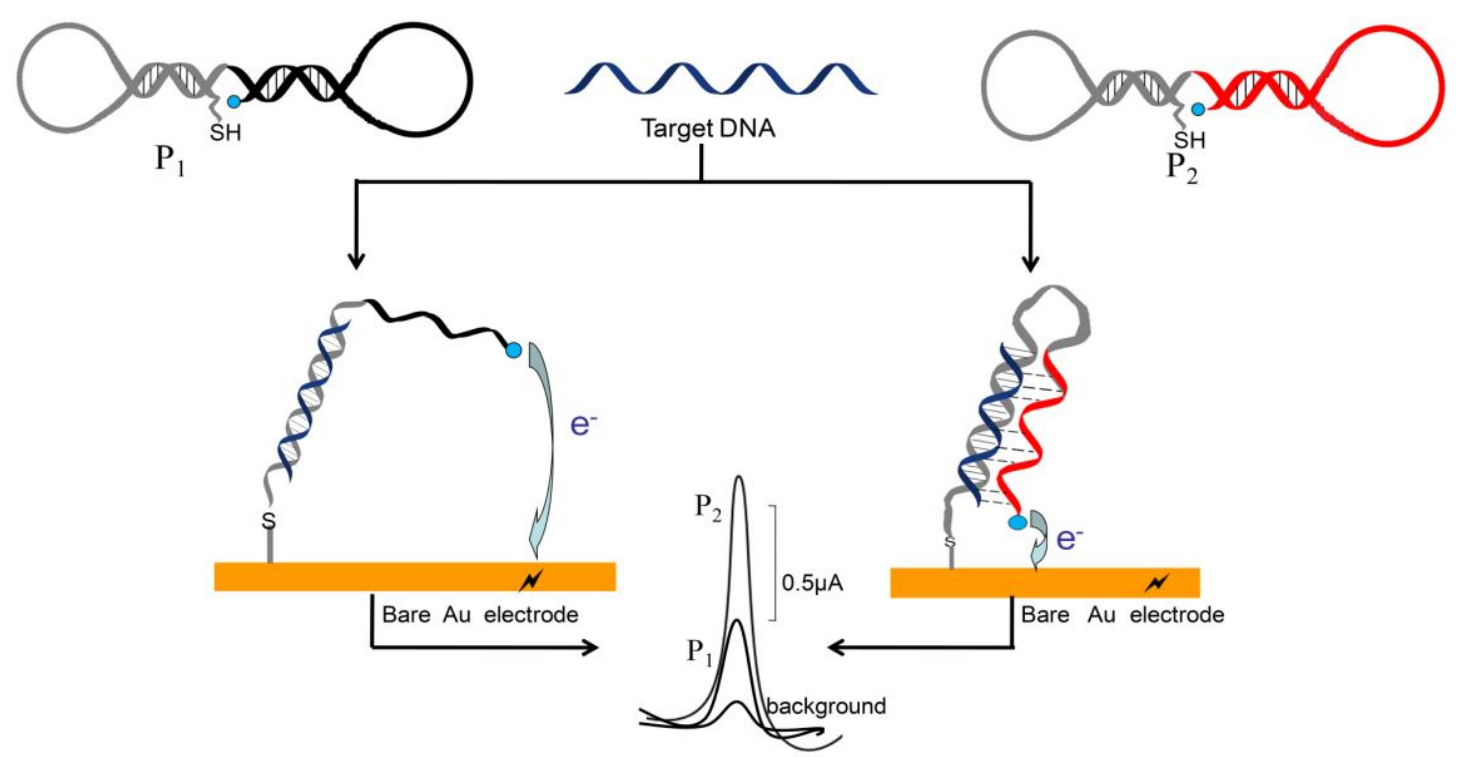


Figure 3

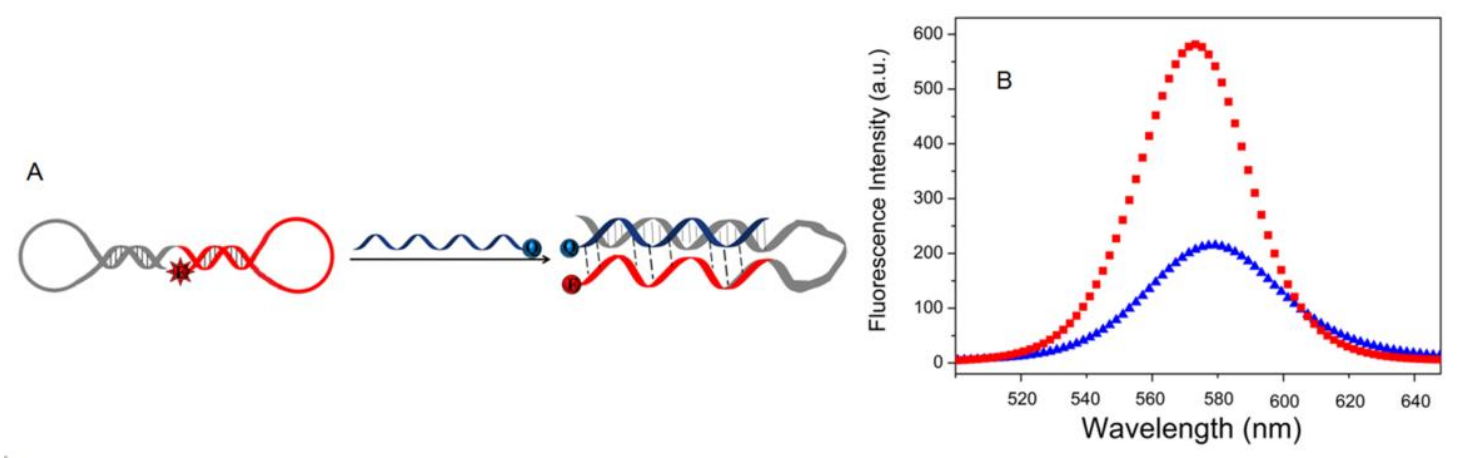

Figure 4

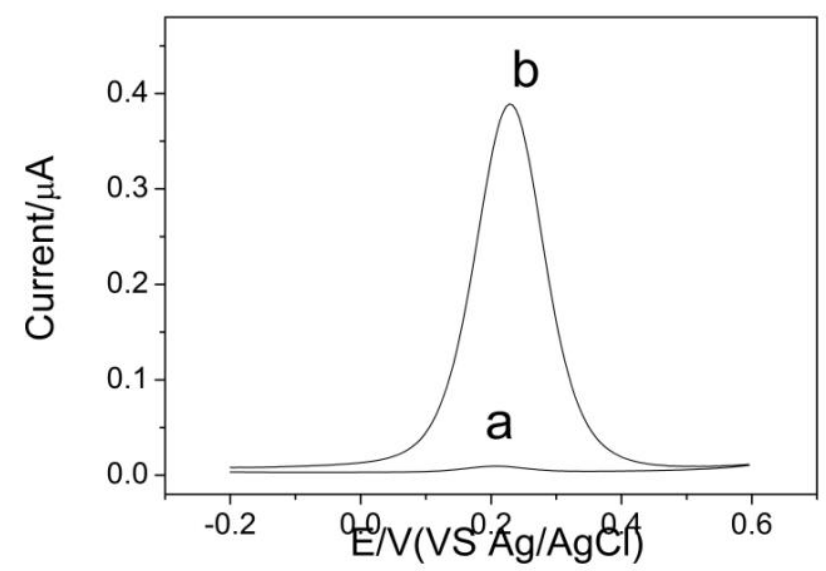


Figure 5
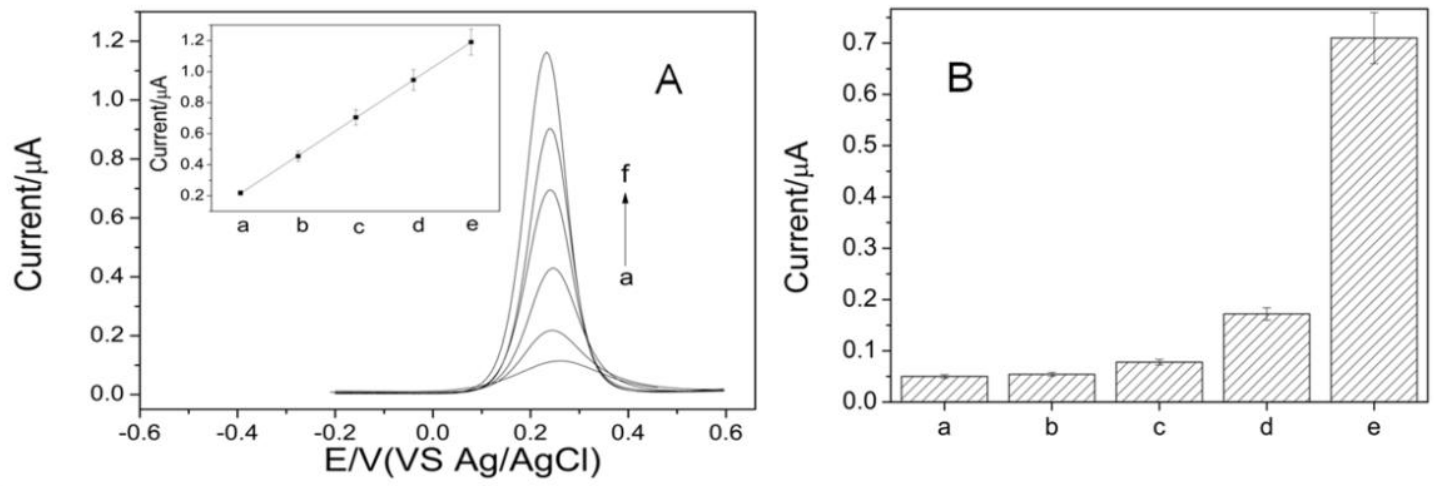